\title{
Mechanical and Physical Properties of Autoclaved Aerated Concrete Reinforced Using Carbon Fibre of Different Lengths
}

\author{
Ilhami DEMIR, Ozer SEVIM*, Mustafa Kagan OGDU, Orhan DOGAN, Sukru DEMIR
}

\begin{abstract}
In this study, series of tests have been conducted to indicate the mechanical and physical properties (compressive strength, flexural strength, dry density, thermal conductivity and shrinkage) of autoclaved aerated concrete (AAC) reinforced with carbon fibres of different lengths. AG2/350 AAC block specimens without carbon fibre were prepared as a control specimen. The mixtures were prepared by replacing $0.5 \%$ weight of cement in the AAC with $4 \mathrm{~mm}, 6 \mathrm{~mm}, 12 \mathrm{~mm}$ length carbon fibres and these mixtures were poured into moulds and subjected to $58{ }^{\circ} \mathrm{C}$ for 4 hours to expand until reaching workable hardness. After preliminary curing, the produced AAC specimens were subjected to $180^{\circ} \mathrm{C}$ and pressure of 11 bar for 6 hours in a steam cure until required hardness. The mechanical and physical properties of the reference and the fibre reinforced AAC specimens were determined and compared to each other. As a result, the use of $12 \mathrm{~mm}$ fibre reinforcement in AAC gave the best performance in comparison to the other fibre reinforcements of different lengths by increasing compressive strength for $10.63 \%$, flexural strength of $31.48 \%$ and thermal conductivity up to $4.23 \%$ while reducing the shrinkage ratio to $51.47 \%$. Herein for the specimen using $0.5 \%$ replacement of the AAC in weight with $12 \mathrm{~mm}$ carbon fibre is recommended.
\end{abstract}

Keywords: autoclaved aerated concrete; carbon fibre reinforcement; compressive strength; dry density; flexural strength; shrinkage; thermal density

\section{INTRODUCTION}

Autoclaved aerated concrete (AAC) is produced by using fine silica-based materials, vesicant materials and binders (cement and/or lime) that are combined with water. Due to the air bubbles it contains, the AAC is a lighter construction material that provides a high level of isolation in comparison to conventional heavy construction materials [1-5].

The biggest step in the production of the AAC was made by J.A.Eriksson and its production began with the method he found in 1924 in Sweden under the patent name Durox [6]. Although not much progress was seen until 1950, it quickly became widespread in Europe and in many other parts of the world after this date [7].

In recent years, supplementary cementitious materials (SCMs), such as silica fume, fly ash, blast furnace slag, bottom ash have been used to improve the properties of AAC [8-13].

Apart from SCMs, fibre reinforcements in AAC production have been material of researches in recent years. Regarding the AAC production with fibre reinforcements, there are many studies in literature [1417].

In the recently conducted studies, it has been shown that carbon fibre reinforcements have provided better results in comparison to plain AAC [18-20]. In their study, Pehlivanli et al. [18] studied the effect of carbon fibre reinforcements on the flexural strength and thermal conductivity values in AAC production. They observed that carbon fibre reinforced AAC showed the best flexural and compressive strengths among other fibre types. Pehlivanlı et al. [19] experimentally studied the change of thermal conductivity, compressive strength and flexural strength of AAC by adding polypropylene, carbon, basalt and glass fibres to the mixture. They observed that the best compressive and flexural strengths were obtained from the carbon fibre reinforced AAC. Laukaitis et al. [20] studied the mechanical properties of carbon fibre reinforced AAC. They stated that the carbon fibre reinforcement increased the flexural strength by $29 \%$.
The flexural strength, compressive strength, dry density, thermal conductivity coefficient and shrinkage values of the AAC are very important factors affecting its usability. Flexural strength is the most important factor among its mechanical properties but, the AAC has very low flexural and impact strengths in comparison to its compressive strength. Therefore, many different studies have been carried out to improve the mechanical properties of the AAC using different fibre reinforcements. However, in the literature, there is no study considering the lengths of the fibre reinforcements. Therefore, herein by adding carbon fibre of different lengths to the AAC as a reinforcement, it is aimed to resist tensile stresses occurring in the AAC under a tension force.

\section{EXPERIMENTAL DESIGN}

\subsection{Materials}

\subsubsection{Carbon Fibre}

In the study, carbon fibres with diameter of 7.2 micron and $4 \mathrm{~mm}, 6 \mathrm{~mm}$ and $12 \mathrm{~mm}$ length were used. The physical and mechanical properties of the carbon fibre used in the experimental study are given in Tab. 1 .

Table 1 Technical properties of carbon fibre

\begin{tabular}{|l|c|}
\hline \multicolumn{1}{|c|}{ Properties } & Carbon Fibre \\
\hline Tensile strength / MPa & 3800 \\
\hline Young's modulus / GPa & 228 \\
\hline Electrical conductivity / $\Omega$-cm & 0.00155 \\
\hline Specific weight & 1.81 \\
\hline Fibre diameter / $\mu \mathrm{m}$ & 7.2 \\
\hline Carbon percentage / \% & 95 \\
\hline
\end{tabular}

\subsubsection{Cement}

CEM I 42.5 R type cement (similar to ASTM Type-I cement) taken from Votorantim Cement was used in this study. It was observed that the physical and chemical properties of the cement were identified as in EN 197-1 and EN 197-2 [21, 22]. The chemical and physical properties of the cement are given in Tab. 2 . 
Table 2 Physical and chemical properties of CEM I 42.5 R type cement

\begin{tabular}{|l|c|}
\hline \multicolumn{1}{|c|}{ Chemical Composition /\% } & Ratio / \% \\
\hline $\mathrm{SiO}_{2}$ & 20.33 \\
\hline $\mathrm{Al}_{2} \mathrm{O}_{3}$ & 5.01 \\
\hline $\mathrm{Fe}_{2} \mathrm{O}_{3}$ & 3.61 \\
\hline $\mathrm{CaO}$ & 61.41 \\
\hline $\mathrm{MgO}$ & 2.38 \\
\hline $\mathrm{SO}_{3}$ & 3.29 \\
\hline $\mathrm{Na}_{2} \mathrm{O} \quad 0.62$ \\
\hline $\mathrm{K}_{2} \mathrm{O} \quad$ & 0.75 \\
\hline \multicolumn{1}{|c|}{ Physical properties } \\
\hline Blaine specific surface area / $\mathrm{cm}^{2} / \mathrm{g}$ & 3481 \\
\hline Initial Setting (min.) & 145 \\
\hline Final Setting (min.) & 210 \\
\hline Specific weight & 3.10 \\
\hline Loss on Ignition / \% & 3.13 \\
\hline Insoluble Residue / \% & 1.38 \\
\hline
\end{tabular}

\subsubsection{Quartzite}

The quartzite used in the study was obtained from the $\mathrm{AKG}$ AAC. Its chemical components and their ratios are given in Tab. 3 .

Table 3 Chemical components and their ratios of the quartzite

\begin{tabular}{|c|c|}
\hline Chemical components $/ \%$ & Quartzite \\
\hline $\mathrm{SiO}_{2}$ & 87.17 \\
\hline $\mathrm{Al}_{2} \mathrm{O}_{3}$ & 2.89 \\
\hline $\mathrm{Fe}_{2} \mathrm{O}_{3}$ & 2.43 \\
\hline $\mathrm{Ti}_{2} \mathrm{O}_{3}$ & 0.21 \\
\hline $\mathrm{K}_{2} \mathrm{O}$ & 1.33 \\
\hline $\mathrm{CaO}$ & 1.91 \\
\hline $\mathrm{MgO}$ & 0.15 \\
\hline $\mathrm{Na}_{2} \mathrm{O}$ & 0.07 \\
\hline
\end{tabular}

\subsubsection{Lime}

The lime obtained from Akyuz Lime Industry was used in the study. It was determined that $\mathrm{CaO}$ ratio in the lime is $85 \%$ and its loss on ignition is $3 \%$.

\subsubsection{Gypsum}

Gypsum was obtained from Silverstone Lime. According to the chemical analysis of gypsum, $\mathrm{CaO}$ ratio is $29.39 \%, \mathrm{SO}_{3}$ ratio is $41.93 \%$, relative humidity is $18.89 \%$ and the loss on ignition is $4.04 \%$.

\subsubsection{Aluminium Powder}

The aluminium powder used in this study was obtained from $\mathrm{AKG}$ the AAC Manufacturing Plant. Aluminium powder/mixture water ratio was taken approximately 1:3.75 in order to obtain aluminium in suspension during AAC production.

\subsubsection{Sludge}

The AAC wastes generated during the production of the AAC are mixed with a certain amount of water and turned into sludge. Obtained sludge was prepared with varying densities between 1.30 and $1.45 \mathrm{~g} / \mathrm{cm}^{3}$.

\subsection{Method}

In this study, the $\mathrm{G} 2 / 350$ grade $\mathrm{AAC}$ used as a wall member (dry density: $350 \mathrm{~kg} / \mathrm{m}^{3}$, compressive strength: 25 $\mathrm{kg} / \mathrm{cm}^{2}$, thermal conductivity coefficient: $0.09 \mathrm{~W} / \mathrm{mK}$ ) was produced as a reference sample. The carbon fibre reinforcement used in the mixture is replaced in the ratio of $0.5 \%$ of the cement in weight. The sludge amount in the AAC mixture prepared for the samples was reduced by $0.5 \%$ of the cement by weight.

By reinforcing the AAC mixtures with $4 \mathrm{~mm}, 6 \mathrm{~mm}$ and $12 \mathrm{~mm}$ length carbon fibres, certain mechanical and physical properties (flexural strength, compressive strength, dry density, shrinkage and thermal conductivity coefficient) of the AAC were examined. The codes of the samples are shown in Tab. 4. For all the experiments conducted, three samples were prepared from each production.

Table 4 The sample codes used in the experimental study

\begin{tabular}{|l|c|}
\hline \multicolumn{1}{|c|}{ Fibre size } & AAC Class \\
\hline Control specimen & G2 \\
\hline Carbon Fibre $4 \mathrm{~mm}$ & G2-CF4 \\
\hline Carbon Fibre $6 \mathrm{~mm}$ & G2-CF6 \\
\hline Carbon Fibre $12 \mathrm{~mm}$ & G2-CF12 \\
\hline
\end{tabular}

In this study, carbon fibre, cement, lime, aluminium, sand mud and water were mixed in various proportions to prepare the AAC mixture. Kilogram quantities of the components in the AAC mixture for $1 \mathrm{~m}^{3}$ are given in Tab. 5 .

Table 5 Quantities of the components in the AAC mixture for $1 \mathrm{~m}^{3}(\mathrm{~kg})$

\begin{tabular}{|c|c|c|c|c|c|c|c|}
\hline Samples & Cement & $\begin{array}{c}\text { Carbon } \\
\text { fibre }\end{array}$ & $\begin{array}{c}\text { Waste } \\
\text { sludge }\end{array}$ & Lime & $\begin{array}{c}\text { Sand } \\
\text { mud }\end{array}$ & Water & A1 \\
\hline Control(G2) & 100 & 0.0 & 150.0 & 30 & 350 & 65 & 0.70 \\
\hline G2-CF4 & 100 & 0.5 & 149.5 & 30 & 350 & 65 & 0.70 \\
\hline G2-CF6 & 100 & 0.5 & 149.5 & 30 & 350 & 65 & 0.70 \\
\hline G2-CF12 & 100 & 0.5 & 149.5 & 30 & 350 & 65 & 0.70 \\
\hline
\end{tabular}

Prior to casting process of the AAC mixture, all the components of mixture are mixed with each other in order. Firstly, the waste sludge and quartzite, gypsum and water mixtures are prepared in different containers and mixed with sand mud in a mixer. Then lime and cement are homogenously dry-mixed and poured into the mixer. By mixing the mixture for about $15-20 \mathrm{sec}$. then adding aluminium suspension and finally casting in a mould, casting operation is completed.

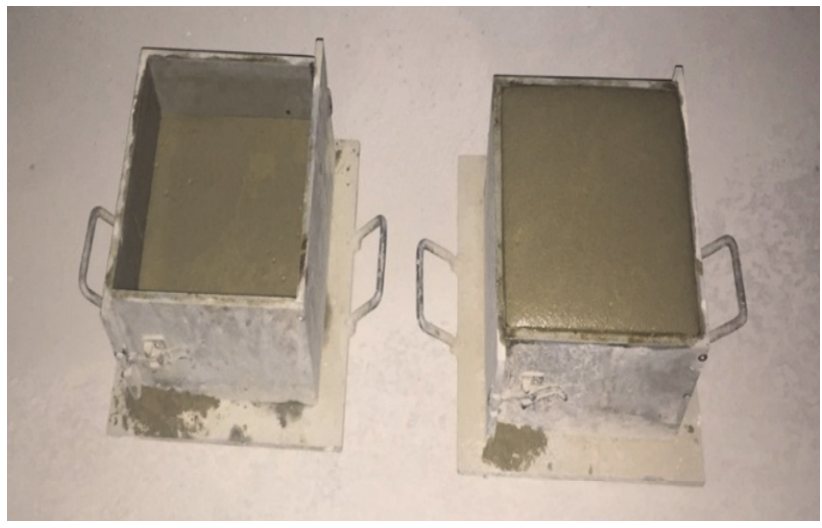

Figure 1 Expansion of AAC mixture into a cake

$\mathrm{Ca}(\mathrm{OH})_{2}$ is produced from the reaction between quicklime and water. Hydrogen gas released from the exothermic reaction between $\mathrm{Ca}(\mathrm{OH})_{2}$ and $\mathrm{Al}$, causes the expansion of the aerated concrete mixture into a cake as shown in Fig. 1 [23]. The chemical reactions that occurred 
after the preparation of the AAC mixture are given in Eq. (1).

$2 \mathrm{Al}+3 \mathrm{Ca}(\mathrm{OH})_{2}+6 \mathrm{H}_{2} \mathrm{O} \rightarrow 3 \mathrm{CaO} \cdot \mathrm{Al}_{2} \mathrm{O}_{3} \cdot 6 \mathrm{H}_{2}+3 \mathrm{H}_{2}$

After completing their chemical reactions and reaching required cake-hardness, the AAC specimens were steam cured in an autoclave. The specimens are subjected to steam curing for 6 hours under a pressure of 11 bar and at a temperature of $180{ }^{\circ} \mathrm{C}$ in the autoclaves (Fig. 2). By subjecting the AAC to steam curing, it is provided with properties of lightness, porous structure and strength.

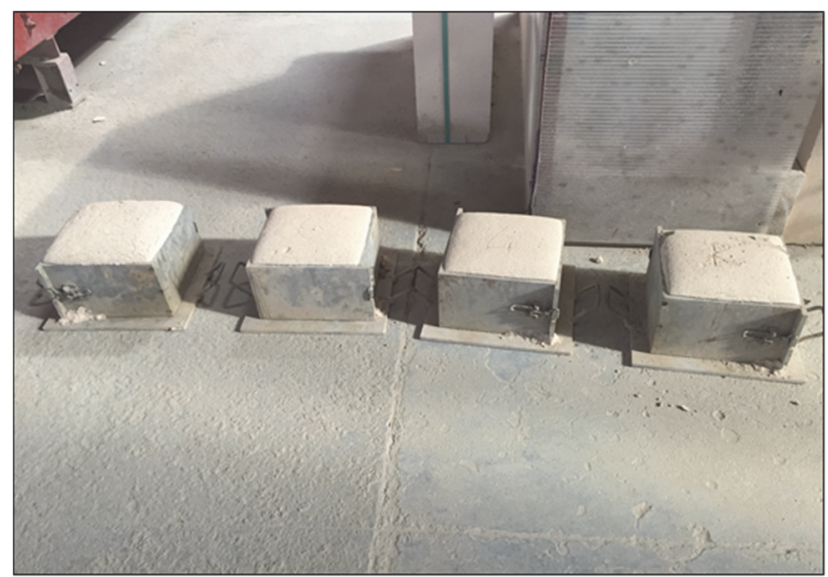

Figure 2 Post-autoclaved aerated concrete

\subsubsection{Determination of Physical Properties and Compressive Strength}

In this study, the compressive strength, flexural strength, dry density, thermal conductivity and shrinkage values of the AAC specimens were experimentally tested.

Compressive Strength. In order to conduct the compressive test, the AAC specimens taken out of the autoclave were cut into dimensions of $100 \times 100 \times 100 \mathrm{~mm}$ and cured in a drying oven at $60{ }^{\circ} \mathrm{C}$ until reducing the moisture amount of the density to $4 \%$. The specimen reached a required humidity according to the EN 772-1 standard was subjected to a continuous and non-impact force with a constant speed $0.1 \mathrm{~N} / \mathrm{s}$ and stress increments $0.05 \mathrm{~N} / \mathrm{mm}^{2} / \mathrm{s}$ until the failure [24].

Dry Density. The dry density test was conducted according to the EN 679 standard [25]. Specimens prepared $100 \times 100 \times 100 \mathrm{~mm}$ in sizes were subjected to the dry density test [25].

Flexural Strength. The flexural strength test was conducted according to the EN 1351 standard [26]. Specimens prepared $50 \times 50 \times 200 \mathrm{~mm}$ in sizes were subjected to the bending moment for flexural test [26].

Thermal Conductivity Test. The thermal conductivity test was conducted according to the EN 12664 standard [27]. The thermal conductivity test of the specimens $300 \times 300 \times 50 \mathrm{~mm}$ in sizes was conducted by the heat flow meter method, using the thermal conductivity device named LASERCOMP FOX 314.

Shrinkage Test. The shrinkage test was conducted according to the EN 680 standard. Specimens $40 \times 40 \times$ $160 \mathrm{~mm}$ in sizes were subjected to the shrinkage test [28].

\section{EXPERIMENTAL RESULTS}

In this experimental study, specimens were produced by mixing water, cement, lime, sand mud and aluminium to make a non-fibre reinforced AAC reference specimen $\mathrm{G} 2 / 350$ (Dry density $350 \mathrm{~kg} / \mathrm{m}^{3}$ ) and G2-CF4, G2-CF6 and G2-CF12 AAC specimen by substituting $0.5 \%$ weight of cement in sand mud with carbon fibres $4 \mathrm{~mm}, 6 \mathrm{~mm}, 12$ $\mathrm{mm}$ respectively in sizes. Series of tests were conducted to determine the compressive strength, flexural strength, dry density, thermal conductivity and shrinkage values of the AAC specimens.

\subsection{Dry Density Properties}

Dry density of the G2 reference specimen was determined as $384.66 \mathrm{~kg} / \mathrm{m}^{3}$ as shown in Fig. 3. The dry densities of the G2-CF4, G2-CF6 and G2-CF12 specimens with carbon fibre decreased by $5.19 \%, 3.47 \%$ and $5.11 \%$ respectively, in accordance to the reference specimens.

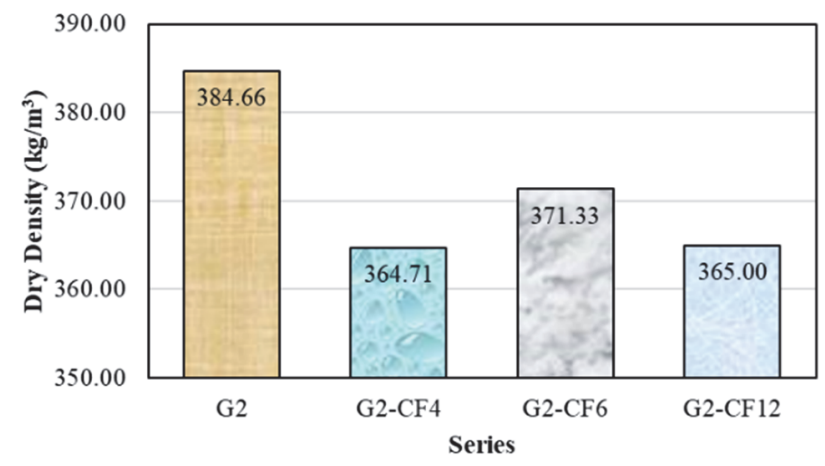

Figure 3 Dry density values of carbon fibre reinforced AACs.

The only difference between the reference $\mathrm{G} 2$ specimen and the other G2-CF4, G2-CF6 and G2-CF12 specimens is the substitution of fibre by $0.5 \%$ in weight with the same amount of cement in the waste sludge. The longer carbon fibres caused an easier release of $\mathrm{H}_{2} \mathrm{O}$ during the reactions. The increment in the release of the gas facilitated the homogeneous expansion of mud. For this reason, the greatest expansion was observed in the specimens substituted with the fibres $12 \mathrm{~mm}$ in length.

\subsection{Compressive Strength}

As shown in Fig. 4, while the compressive strength value of the reference $\mathrm{G} 2$ specimen was $2.48 \mathrm{~N} / \mathrm{mm}^{2}$, in comparison to the compressive strength of the reference specimen, the compressive strengths of the G2-CF4, G2CF6 and G2-CF12 specimens increased with the ratios of $8.2 \%, 9.2 \%, 10.63 \%$, respectively.

There is a direct proportion between density and the compressive strength of the AAC. However, as shown in Fig. 3 and Fig. 4, there is an increment in compressive strengths, while the density of the fibre-reinforced specimens decreases. It is understood that the fibres have an important role in bridging the micro-cracks formed due to stress and increased its stress capacity. It is understood from the literature that in comparison to the well-known AAC without fibres, carbon fibres caused an increase in compressive strength $[18,19]$. 


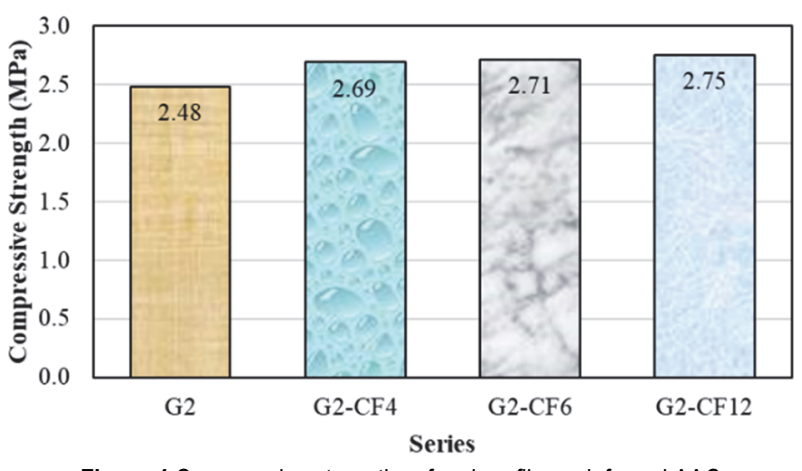

Figure 4 Compressive strengths of carbon fibre reinforced AAC

\subsection{Flexural Strength}

As shown in Fig. 5, the flexural strength of the reference G2 specimen is measured as $0.54 \mathrm{~N} / \mathrm{mm}^{2}$. The flexural strengths of the G2-CF4, G2-CF6 and G2-CF12 specimens were increased in comparison to the reference G2 specimen. There is a direct proportion between the flexural strength of AAC and the fibre lengths as $13.33 \%$, $18.52 \%, 31.48 \%$, respectively.

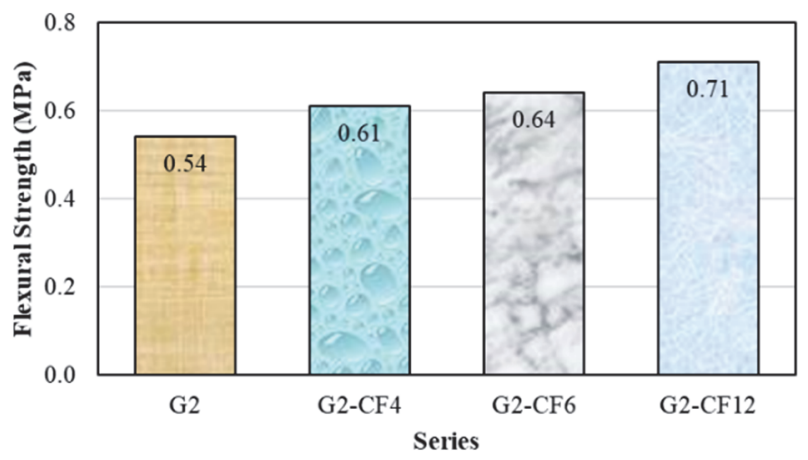

Figure 5 Flexural strength of carbon fibre reinforced AACs

It is believed that the carbon fibres resist to stress generated between surfaces forced to break apart from each other during the bending test. At the same time, longer fibres enable greater adherence. The increment of the carbon fibre length increases tensile strength of the AAC. Therefore, the flexural strength also increases depending on the tensile strength. Similar to the literature, due to the use of carbon fibre, an increase of the flexural tensile strength of the AAC specimens has been seen $[18,19]$.

\subsection{Thermal Conductivity}

The thermal conductivity coefficient of the reference G2 specimen, as shown in Fig. 6, was measured as 0.08534 $\mathrm{W} / \mathrm{mK}$. In comparison to the reference G2 specimen, the thermal conductivity coefficients of the G2-CF4, G2-CF6 and G2-CF12 specimens increased by $3.19 \%, 5.36 \%$ and $4.23 \%$, respectively.

Due to the homogenous distribution of the carbon fibres used in the G2-CF4, G2-CF6 and G2-F12 specimens, the heat bridge formations increase the thermal conductivity, as shown in Fig. 6. Similar to the previous study, it is seen that fibre reinforced AACs increased thermal conductivity [19].

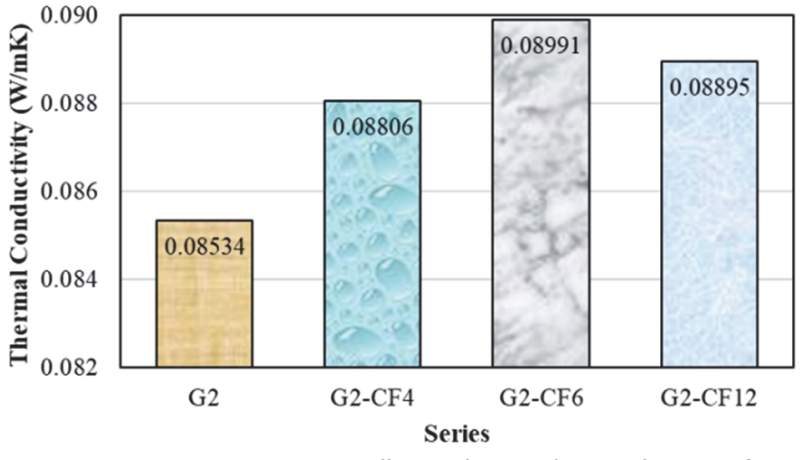

Figure 6 Thermal conductivity coefficient of carbon fibre reinforced AACs

\subsection{Shrinkage Properties}

As shown in Fig. 7, the shrinkage of the reference G2 specimen was measured as $0068 \mathrm{~mm} / \mathrm{m}$. In comparison to this reference, the shrinkage of the G2-CF4, G2-CF6 and G2-CF12 specimens decreased by $16.18 \%, 25 \%, 51.47 \%$, respectively.

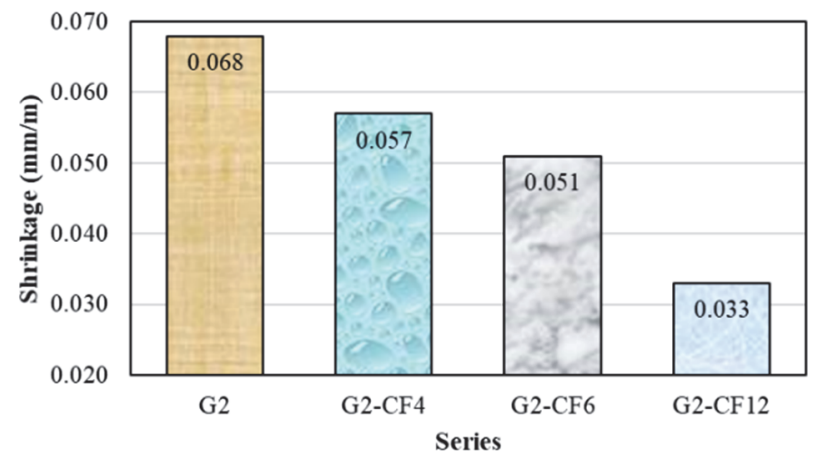

Figure 7 Shrinkage of carbon fibre reinforced AACs

Depending on the increase of the fibre length, the shrinkage of the G2-CF4, G2-CF6 and G2-CF12 specimens decreased, but the rate of utilization of the tensile strength of fibres increased. It is believed that fibres prevent the growth of micro-cracks by compensating the stresses caused by contractions occurring during hydration. The shrinkage decrease has a positive effect on the compressive strength.

\section{CONCLUSIONS}

In this study, carbon fibre was substituted at the rate of $0.5 \%$ of cement in weight into the reference G2/350 (350 $\mathrm{kg} / \mathrm{m}^{3}$ ) class of AAC used as a masonry wall element. Waste sludge was reduced at the same rate as added carbon fibre. The results given below were obtained.

Although the density of the carbon fibre reinforced specimen decreased, an improvement was observed in their compressive strengths. It was observed that the carbon fibres increase the load-bearing capacity due to the adherence provided between the micro-cracks formed by the stresses during the test.

Shrinkage of all the carbon fibre reinforced specimens decreased and caused an increase of compressive strength.

It was observed that the carbon fibres resist the stress between surfaces forced to break apart from each other during the bending test. At the same time, the longer fibres enable greater adherence. The increment of the carbon 
fibre length increases the tensile strength of the AAC. Therefore, the flexural strength also increases depending on the tensile strength.

Due to the homogeneous distribution of the carbon fibres used in the G2-CF4, G2-CF6 and G2-F12 specimens, the heat bridge formations increase the thermal conductivity.

As a result, in comparison to the reference specimen, the AAC specimens prepared by using different sizes of carbon fibre, caused positive effects on compressive strength, flexural strength, dry density and shrinkage properties, while causing negative effects on thermal conductivity.

Additionally, the substitution of $0.5 \%$ cement in weight with $12 \mathrm{~mm}$ carbon fibre gave the best performance with an increment of $10.89 \%$ in compressive strength, $31.48 \%$ in flexural strength, $4.23 \%$ in thermal conductivity and a decrement of $51.47 \%$ in shrinkage.

\section{REFERENCES}

[1] TS EN 12602 (2016). Prefabricated reinforced components of autoclaved aerated concrete. Ankara: Turkish Standard Institution.

[2] Schreiner, J., Jansen, D., Ectors, D., Goetz-Neunhoeffer, F., Neubauer, J., \& Volkmann, S. (2018). New analytical possibilities for monitoring the phase development during the production of autoclaved aerated concrete. Cement and Concrete Research, 107, 247-252. https://doi.org/10.1016/j.cemconres.2018.02.028

[3] Li, X., Liu, Z., Lv, Y., Cai, L., Jiang, D., Jiang, W., \& Jian, S. (2018). Utilization of municipal solid waste incineration bottom ash in autoclaved aerated concrete. Construction and Building Materials, 178, 175-182. https://doi.org/10.1016/j.conbuildmat.2018.05.147

[4] Liu, Y., Leong, B. S., Hu, Z. T., \& Yang, E. H. (2017). Autoclaved aerated concrete incorporating waste aluminum dust as foaming agent. Construction and Building Materials, 148, 140-147. https://doi.org/10.1016/j.conbuildmat.2017.05.047

[5] Chen, Y. L., Chang, J. E., Lai, Y. C., \& Chou, M. I. M. (2017). A comprehensive study on the production of autoclaved aerated concrete: Effects of silica-lime-cement composition and autoclaving conditions. Construction and Building Materials, 153, 622-629. https://doi.org/10.1016/j.conbuildmat.2017.07.116

[6] Eriksson, J. A. (1925) U.S. Patent No. 1,546,221. Washington, DC: U.S. Patent and Trademark Office.

[7] Balkema, A. A. (1992) Advances in Autoclaved Aerated Concrete. F. H. Wittmann (Ed.). Roterdam: A. A. Balkema.

[8] Kurama, H., Topcu, I. B., \& Karakurt, C. (2009). Properties of the autoclaved aerated concrete produced from coal bottom ash. Journal of materials processing technology, 209(2), 767-773 https://doi.org/10.1016/j.jmatprotec.2008.02.044

[9] Wongkeo, W. \& Chaipanich, A. (2010). Compressive strength, microstructure and thermal analysis of autoclaved and air cured structural lightweight concrete made with coal bottom ash and silica fume. Materials Science and Engineering: A, 527(16-17), 3676-3684. https://doi.org/10.1016/j.msea.2010.01.089

[10] Huang, X. Y., Ni, W., Cui, W. H., Wang, Z. J., \& Zhu, L. P. (2012). Preparation of autoclaved aerated concrete using copper tailings and blast furnace slag. Construction and Building Materials, 27(1), 1-5. https://doi.org/10.1016/j.conbuildmat.2011.08.034

[11] Ma, B. G., Cai, L. X., Li, X. G., \& Jian, S. W. (2016). Utilization of iron tailings as substitute in autoclaved aerated concrete: physico-mechanical and microstructure of hydration products. Journal of Cleaner Production, 127, 162-171. https://doi.org/10.1016/j.jclepro.2016.03.172

[12] Mitsuda, T., Sasaki, K., \& Ishida, H. (1992). Phase evolution during autoclaving process of aerated concrete. Journal of the American Ceramic Society, 75(7), 1858-1863. https://doi.org/10.1111/j.1151-2916.1992.tb07208.x

[13] Mostafa, N. Y. (2005). Influence of air-cooled slag on physicochemical properties of autoclaved aerated concrete. Cement and Concrete Research, 35(7), 1349-1357. https://doi.org/10.1016/j.cemconres.2004.10.011

[14] Dey, V., Bonakdar, A., \& Mobasher, B. (2014). Lowvelocity flexural impact response of fiber-reinforced aerated concrete. Cement and Concrete Composites, 49, 100-110. https://doi.org/10.1016/j.cemconcomp.2013.12.006

[15] Mousa, M. A. \& Uddin, N. (2009). Experimental and analytical study of carbon fiber-reinforced polymer (FRP)/autoclaved aerated concrete (AAC) sandwich panels. Engineering Structures, 31(10), 2337-2344. https://doi.org/10.1016/j.engstruct.2009.05.009

[16] Uddin, N., Fouad, F. H., Vaidya, U. K., Khotpal, A. K., \& Serrano-Perez, J. C. (2007). Structural behavior of fiberreinforced polymer-autoclaved aerated concrete panels. $A C I$ Structural Journal, 104(6), 722. https://doi.org/10.14359/18954

[17] Serrano-Perez, J. C., Vaidya, U. K., \& Uddin, N. (2007). Low velocity impact response of autoclaved aerated concrete/CFRP sandwich plates. Composite structures, 80(4), 621-630. https://doi.org/10.1016/j.compstruct.2006.07.013

[18] Pehlivanl, Z. O., Uzun, İ., \& Demir, İ. (2018). Mechanical and microstructural features of autoclaved aerated concrete reinforced with autoclaved polypropylene, carbon, basalt and glass fiber. Construction and Building Materials, 96, 428-433. https://doi.org/10.1016/j.conbuildmat.2015.08.104

[19] Pehlivanl, Z. O., Uzun, I., Yücel, Z. P., \& Demir, İ. (2016). The effect of different fiber reinforcement on the thermal and mechanical properties of autoclaved aerated concrete. Construction and Building Materials, 112, 325-330. https://doi.org/10.1016/j.conbuildmat.2016.02.223

[20] Laukaitis, A., Jadvyga, K., Modestas, K., Donatas, M., \& Lina, L. (2012). Influence of mechanically treated carbon fibre additives on structure formation and properties of autoclaved aerated concrete. Construction and Building Materials, 26, 362-371. https://doi.org/10.1016/j.conbuildmat.2011.06.035

[21] TS EN 197-1. (2012). Cement-Part 1: Composition, specifications and conformity criteria for common cements. Turkish Standard Institution. Ankara: Turkish Standard Institution.

[22] TS EN 197-2. (2014). Cement-Part 2: Conformity evaluation. Ankara: Turkish Standard Institution.

[23] Mostafa, N. Y. (2005). Influence of air-cooled slag on physicochemical properties of autoclaved aerated concrete. Cement and Concrete Research, 35(7), 1349-1357. https://doi.org/10.1016/j.cemconres.2004.10.011

[24] TS EN 772-1. (2015). Methods of test for masonry units-Part 1: Determination of compressive strength. Ankara: Turkish Standard Institution.

[25] TS EN 678. (1995). Determination of the Dry Density of Autoclaved Aerated Concrete. Ankara: Turkish Standard Institution.

[26] TS EN 1351. (1998). Determination of Flexural strength of auto laved aerated concrete. Ankara: Turkish Standard Institution.

[27] TS EN-12664. (2001). Thermal performance of building materials and products-Determination of thermal resistance by means of guarded hot plate and heat flow meter methods - Dry and moist products of medium and low thermal resistance. Ankara: Turkish Standard Institution.

[28] TS EN 680. (2006). Determination of the drying shrinkage of autoclaved aerated concrete. Ankara: Turkish Standard Institution. 


\section{Contact information:}

Ilhami DEMIR, PhD, Professor

Kırıkkale University,

Department of Civil Engineering,

71451, Yahsihan, Kırıkkale, Turkey

E-mail: ildemir@kku.edu.tr

Ozer SEVIM, PhD, Assistant Professor

(Corresponding author)

Kırıkkale University,

Department of Civil Engineering,

71451, Yahsihan, Kırıkkale, Turkey

E-mail: ozersevim@kku.edu.tr

\section{Mustafa Kagan OGDU, MSc}

Kırıkkale University,

Department of Civil Engineering,

71451, Yahsihan, Kırıkkale, Turkey

E-mail:mc_agan@hotmail.com

Orhan DOGAN, PhD, Associate Professor

Kırıkkale University,

Department of Civil Engineering

71451, Yahsihan, Kırıkkale, Turkey

E-mail: odogan@kku.edu.tr

Sukru DEMIR, MSc Student

Kırıkkale University,

Department of Civil Engineering,

71451, Yahsihan, Kırıkkale, Turkey

E-mail:sukrucan06_40@hotmail.com 